were some rooms in the Hospital Rosales of El Salva. dor. In 1931 the local Red Cross opened the first public dispensary and founded the National Anti-tuberculosis League. Five years later another dispensary was opened at Santa Ana. In 1939 the director of health created a Department of Tuberculosis and in 1940 opened a new dispensary where 14,000 examinations were made and 93 per cent of the contacts were investigated, while 5,000 homes were visited. In 1938 the first census was taken to determine the amount of infections among school children in the capital ; 4,151 were examined. The Montoux and Pirquet tests were found to be positive in 32.8 per cent of the five to six year olds, and in 62 per cent of those aged 14-15. Similar results were obtained in Santa Ana in 1939. Of 12,000 apparently healthy persons at El Salvador in a population of 100,000 , 1.42 per cent showed signs of active tuberculosis. Recent figures showed a distribution of 22 per cent, 64 per cent and 14 per cent among the minimal, moderate and advanced lesions respectively, which are very encouraging figures compared with those of 1932, when about 72 per cent of the cases showed advanced lesions.

\section{Suppressing High-Frequency Disturbances from Telephone Apparatus}

IN an article by M. E. Krom (Bell Lab. Rec., 20, No. 10, June 1942) it is pointed out that disturbances such as those arising from the opening of the contacts of a telephone dial may be represented by an infinite number of alternating currents extending upwards through the entire radio spectrum. Disturbances of this type may reach receivers by direct radiation, by coupling between the telephone line and receiving antenna, or by secondary coupling via some outside electrical system such as a power line. Two general types of suppression devices are available to limit noise influence. One, located at the source, tends to reduce the radio-frequency voltages developed ; the other-usually remote from the source -is functionally a low pass filter. The former type most commonly consists of a small inductance and capacitance connected across the dial contacts. The inductance prevents too rapid a build-up of current as the contacts close whilst the capacitance reduces the voltage on the telephone line as they open.

The filter action results in the voltage increasing slowly as the contacts open, instead of producing a series of high-frequency surges, and $40-55 \mathrm{db}$. suppression is obtained. Another type of filter similar in action but of different characteristics, is used to suppress radio-frequency voltages from teleprinters and affords some $50-60 \mathrm{db}$. suppression over the range of from $200-30,000 \mathrm{kc}$. The disturbances from power plant associated with telephone equipment are usually effectively suppressed $(20-25 \mathrm{db}$.) by simple condensers. Where the individual sources of noise are numerous the second general type of device-the low pass filter-is used, and it may consist of an inductance connected in series with each side of the line, the outgoing ends of which are terminated by a condenser connected to earth. It is desirable that inductive elements used in radio filters have a high effective resistance over a wide band of frequencies instead of a peaked impedance at the resonant frequency.

\section{Man-Made Radio Interference}

AN article by R. A. Shetzline (Bell Lab. Rec., 20, No. 10, June 1942) reviews the factors involved in this increasingly important subject. Opening with a brief reference to the multi-frequency disturbances caused by the operation of a relay or switch, the author cites an example of a telephone line and an adjacent power line as a source of interference to a nearby radio receiver. Attention is directed to the signal-to-noise ratio of a receiver as the criterion of its performance, and it is shown how this ratio is dependent on the field intensity of the received radio signal and on the effectiveness of the antenna, the latter being a function of the effective height of the antenna and the impedance relations between antenna and receiver.

Expressions are evolved from which it becomes apparent that the best radio reception is obtained when the field intensity, antenna efficiency, line coupling loss and the attenuation along the line are greatest; the latter depends upon whether the line be cable or open wire. Interference by direct radia. tion becomes of importance only when the source is close to the antenna or on the same premises as the receiver. Experience has shown that in many instances noisy reception reports arise only when distant stations are sought. With field strengths of reasonable values, and with suitable antenna circuits, simple preventive measures should mitigate the annoyance caused to radio listeners by telephone apparatus.

\section{The Night Sky in September}

The moon is new on September 10d. 15h. 53m. U.T. and full on September 24d. 14h. 34m. The following conjunctions will occur during the month : Sept. 2 d. $20 \mathrm{~h}$., Saturn in conjunction with the moon, Saturn $3^{\circ}$ N. ; Sept. 6d. 00h., Jupiter in conjunction with the moon, Jupiter $4^{\circ}$ N. ; Sept. 9d. 05h., Venus in conjunction with the moon, Venus $2^{\circ}$ N. ; Sept. 9d. 15h., Venus in conjunction with Regulus, Venus $0 \cdot 7^{\circ}$ N. ; Sept. 12d. 15h., Mercury in conjunction with the moon, Mercury $6^{\circ} \mathrm{S}$.; Sept. 30d. 05h., Saturn in conjunction with the moon, Saturn $3^{\circ} \mathrm{N}$. Mercury, in greatest elongation, $27^{\circ}$, on Sept. 15, is an evening star and unfavourably placed for observation for northern observers. Venus is a morning star, and Jupiter in Gemini is well placed for observation in the morning. Saturn and Uranus are not very far from Aldebaran and appear in the east before midnight. No occultations of any bright stars will occur during the month. The longer evenings provide an opportunity for seeing many interesting sights such as the Pleiades, the variable star Algol, the Great Nebula of Andromeda close to the star $\vee$ Andromedæ, and other objects of interest.

There will be a partial eclipse of the sun on Sept. 10, visible at Greenwich. The circumstances of the eclipse at Greenwich are as follows :

$$
\begin{array}{cccc}
\text { Magnitude } & \text { Eclipse begins } & \text { Greatest phase } & \text { Eclipse ends } \\
0.33 & 15 \mathrm{~h} .24 \mathrm{~m} . & 16 \mathrm{~h} .17 \mathrm{~m} . & 17 \mathrm{~h} .07 \mathrm{~m} .
\end{array}
$$

\section{Announcements}

Sir Henry Dale, who was recently appointed a member of the Governing Body of the Lister Institute of Preventive Medicine, has been elected by the Board as its chairman.

An open meeting of the Association of Scientific Workers will be held on September 4 at 7 p.m. at the Caxton Hall, London, S.W.l, to discuss and support proposals for a Central Scientific and Technical Board. The speakers will include Lord Strabolgi. 